\title{
Mosaico do vir a ser uma Professora de Ciências: por entre Memórias de Escolarização, Histórias de Vida e Sentimentos da Docência
}

\author{
The Mosaic of becoming a Science Teacher: Amid Memories \\ of Schooling, Life Histories and Feelings about Teaching
}

\author{
Sebastião Rodrigues-Moura' \\ Dintia Aliny Silva de Souza² \\ Silvaney Fonseca Ferreira Seabra² \\ Terezinha Valim Oliver Gonçalves ${ }^{3}$ \\ 'Instituto Federal de Educação, Ciência e Tecnologia do Pará (IFPA), Belém, PA, Brasil. \\ Autor Correspondente: sebastiao.moura@ifpa.edu.br \\ ${ }^{2}$ Secretaria Executiva de Estado de Educação do Pará (SEDUC), Belém, PA, Brasil. \\ ${ }^{3}$ Universidade Federal do Pará (UFPA), Belém, PA, Brasil.
}

Resumo: Neste artigo analisamos as narrativas formativas que constituem o processo de imersão na docência entre memórias de experiências vivenciadas, histórias de vida relatadas, e sentimentos expressos por uma professora de ciências. À professora, em contexto investigativo, foi proposta a escrita de uma carta a um professor que houvesse participado do seu percurso formativo e, posteriormente, fizemos uma entrevista semiestruturada para elucidar aspectos memorialísticos, cujas manifestações foram analisadas à luz dos referenciais da Análise Textual Discursiva, das quais emergiram dois filetes de análise no espaço-tempo das narrativas. Os resultados apontam que os sentimentos expressos estão narrativamente relacionados com o processo de introspecção e extrospecção do (re)contado e (re)vivido pela professora, bem como as contribuições do vir a ser professora circulam no movimento retrospectivo e prospectivo que moldam a sua prática, fortemente entrelaçados em um mosaico de experiências que a acompanham no presente e se projetam ao futuro.

Palavras-chave: Memórias de docência; História de vida; Pesquisa narrativa; Narrativas de professores.

Abstract: In this research, we analyze how formative narratives that make up the process of immersion into memories of lived experiences, related life histories and feelings expressed by a science teacher. To that teacher (participant), in an investigative context, it was proposed the writing of a letter to another teacher who might have participated in the participant's formative journey and, subsequently, a semi-structured interview was conducted to elucidate memory aspects, the manifestations of which were analyzed in light of Discursive Textual Analysis (TDA), from which two threads of analysis arose in the space-time of the narratives. The results indicate that the expressed feelings are related in a comparative way with the process of introspection and extrospection of what is (re)counted and (re)-experienced by the teacher. In addition, the contributions of becoming a teacher circulate in the retrospective and prospective movements that shape her practice, and are strongly intertwined in a mosaic of experiences that accompany her in the present and project themselves into the future.

Keywords: Teaching memories; Life histories; Narrative inquiry; Teacher narratives.

Recebido em: $31 / 03 / 2020$

Aprovado em: 07/06/2020 


\section{À Guisa de Introdução}

Os relatos memorialísticos de professores têm sido desenvolvidos/utilizados em pesquisas educacionais como ferramentas investigativas para compreender histórias e percursos de vida, escolarização e formação, bem como dar sentidos e construir significados acerca de sentimentos mais profundos dos encantos pela docência, desde a formação da pessoa no seu meio, como as confluências relacionais do processo relacional e os saberes construídos para a prática, em um processo reflexivo (FRAIHA-MARTINS, 2014; GONÇALVES, 2010; JOSSO, 1999). Os relatos que emergem das memórias dos professores são esboçados na relação com o outro, permitem refazer suas histórias, lembranças, desejos e conflitos da sua vivência, por meio do narrar, do viver, do reviver, do contar e recontar as experiências situadas no contexto espaço-temporal, frente a uma sinergia e miscelânea da própria experiência (CLANDININ; CONNELLY, 2015; SOUSA; CABRAL, 2015).

Em um sentido coplanar das investigações qualitativas da experiência, as histórias de vida ganham espaço por tecer elementos que podem ser analisados com mais aprofundamento como motivações, valores, comportamentos e escolhas da carreira, uma vez que os participantes conseguem traçar estratégias de vida pessoal e profissional, perspectivas e projeções para o mundo social e profissional, influenciados pelo meio e pelas limitações das estruturas sociopolíticas (CLOSS; ROCHA-DE-OLIVEIRA, 2015; DELORY-MOMBERGER, 2012; SMITH, 2012). Josso (1999, p. 19) aponta que tais estratégias de narrativas "[...] abarcam a totalidade da vida em todos os seus registros, nas dimensões passadas, presentes e futuras e, portanto, em sua dinâmica global".

No tocante à formação de professores, ouvir as histórias de vida nos conduzem aos espaços formativos diante da sua natureza, dos contextos experienciados e das influências que possam vir a caracterizar sentidos e significados na ação docente e no seu desenvolvimento profissional, bem como destacar o ser professor, pela maneira que se constitui em sua abordagem didático-pedagógica e epistemológica. Dessa forma, acrescem (res)significações de reflexão para a prática, o posicionamento crítico adotado, bem como o processo de (auto)reflexão pedagógica e de autorregulação do modo de ensinar e aprender que são construídas na identidade do profissional (BURNIER et al., 2007; GOODSON, 1992; PASSEGGI, 2012).

O extasiar-se e oncantar-se pela docência sejustifica com claras e verdadeiras razões de uma decisão pessoal para uma projeção profissional, momento no qual se desvendam malhas, filetes e insights tão eficientes da vida, que estruturam e são reconhecidos pelo professor, ao penetrar no seu mundo imaginário e simbólico de vida, criando um mosaico daquilo que configura o seu universo racional (FERREIRA; FERNANDES; ALBERT, 2000; GIORDANO, 2013). O cerne desses encantamentos memorialísticos do professor atribui relevância à pesquisa, trazendo à tona sentimentos do processo de escolarização, rumores, situações experienciadas, silêncios, sonhos, hesitações, obstáculos, admirações e sentimentos para com terceiros que perpassaram pelos lapsos da sua vida.

Do exposto, nossa inquietação neste artigo surge como meio de investigar em que termos formativos são expressas narrativas que constituem a docência de uma professora de ciências a partir de suas memórias de escolarização, histórias de vida e sentimentos experienciados? Os filetes para responder essa problemática surgem da vivência da participante da pesquisa, professora em processo de formação doutoral, por 
meio de propostas desenvolvidas para (re)viver e (re)contar narrativas do seu processo de escolarização expressas em uma carta sobre o que aprendeu com um professor que marcou a vida dela e, a posteriori, notas de uma entrevista realizada sobre os elementos analisados na carta e a experiência da professora.

Com vistas ao atendimento dos nossos propósitos de pesquisadores e na busca por elementos dessas narrativas, levantamos a tese de que o percurso de formação e docência se constitui de narrativas que tecem um mosaico de experiências vividas, expressando sentidos, significados e sentimentos relativos à docência e à profissão, sob um olhar dual, como aluna no passado e como professora no presente. Nesse sentido, neste artigo voltamos nossos olhares de pesquisadores qualitativos para analisar as narrativas formativas que constituem o processo de imersão na docência por entre memórias de experiências vivenciadas, histórias de vida relatadas e sentimentos expressos por uma professora de ciências.

Ao estabelecer um mosaico para esta investigação, configuramos essa metáfora no sentido de embutir os filetes de memórias de escolarização da professora pesquisada, o afeto que preenche a dimensão espaço-temporal para com um professor, pelo qual expressa profunda admiração e os caminhos de convergências para o ser docente, elementos que se entrelaçam e configuram uma história do vir a ser uma professora de ciências.

Ancoramo-nos, nesta investigação de abordagem qualitativa, nos maiores expoentes da pesquisa narrativa, Clandinin e Connely (2015), inspirados em John Dewey, mais especificamente na palavra-chave "experiência", por considerar o espaço-tempo em que acontecem e produzem interações relacionais formativas relevantes. $O$ pensamento narrativo tem um aspecto temporal, nas direções do ir e vir ao passado e ao futuro (retrospectivo e prospectivo) e em relações sociais (introspecção e extrospecção), em um âmbito tridimensional, considerando-se os aspectos do presente, passado e futuro (dimensão temporal), os caracteres social e pessoal (dimensão relacional), bem como o retrato de um cenário/uma paisagem, onde ocorrem situações, eventos, lugares ou fatos (dimensão situacional) vividos e narrados.

\section{Tessitura Metodológica}

Assumimos, nesta investigação, um tecer metodológico da pesquisa qualitativa, de abordagem narrativa, como método de pesquisa e, ao mesmo tempo, o fenômeno pesquisado, como ensinam os autores-referência, a fim de delinearmos de forma concisa, coerente, clara e precisa os elementos que adotamos como referencial de suporte na singularidade da compreensão da pessoa, de sua experiência e das vivências coletivas e individuais, fundamentais para contextualizar a sua realidade. Situamos a presente discussão em uma dimensão espaço-tempo, pelo fato de as narrativas consistirem em arranjos nos quais os sujeitos envolvidos na pesquisa se situam e se movimentam em determinado espaço em que decorrem os aspectos temporais; tais fatores são essenciais para que possamos nos situar por entre os caminhos das investigações (CLANDININ; CONNELY, 2015).

Visando encontrar elementos narrativos, assumimos a pesquisa qualitativa, com base em Minayo (2012), por buscarmos elementos discursivo-argumentativos, com ancoragem em um escopo e no emprego de informações precisas da literatura da área, buscando a 
compreensão do objeto de estudo. Abarcamos os elementos das vivências e da experiência da professora de Ciências, de modo a compreender o seu contexto e, dessa forma, adotar procedimentos mais organizados, aproximados e familiares para com o objeto, bem como a apresentação dos resultados, de uma forma adequada e acessível frente às narrativas.

A colaboradora desta pesquisa é a professora Renata (nome fictício), bióloga em formação doutoral em uma universidade pública da região Norte do país. É professora de Ciências que atuou por alguns meses na Educação Básica, porém, há quatro anos, desenvolve suas atividades profissionais como docente de uma Instituição de Ensino Superior na linha de Educação em Ciências, de maneira mais específica nas disciplinas de Estágio Supervisionado e Práticas Pedagógicas.

Como instrumentos para a coleta de dados utilizamos uma carta escrita por ela, em contexto investigativo, e uma entrevista narrativa, como dito anteriormente, as quais são materiais empíricos da nossa investigação, na coleta dos textos de campo para compor os textos de pesquisa. As cartas são textos de campo que valorizam a reflexão, as experiências vividas e as manifestações de afeto, pelas quais podemos ter acesso aos significados na dinâmica da vida que a pessoa constrói sobre si (CLANDININ; CONNELY, 2015; STRYKER; BURKE, 2000).

Os relatos memorialísticos advindos das entrevistas, por sua vez, emergem como notas de campo não estruturadas, nas quais procuramos compreender aspectos específicos expressos na carta. Assim, a partir das memórias e histórias de vida relatadas pela professora, tendo como base o recontar do acontecimento em pauta, com uso de uma linguagem espontânea e fluida, de forma colaborativa interativa e dialogada (JOVCHELOVICH; BAUER, 2002; CLANDININ; CONNELY, 2015), construímos tessituras de vida e formação, compreendendo sentidos e significados das experiências vividas e relatadas.

Para a análise dos textos de campo (relatos escritos e orais), optamos pelo uso da Análise Textual Discursiva (ATD), proposta por Moraes e Galiazzi (2011), como técnica de análise de dados qualitativos, a fim de produzir sentidos e tecer argumentos dos dados que emergem como forma de dar significado às memórias e às histórias de vida narradas pela professora de Ciências. As experiências vividas por ela, desde o seu processo de escolarização até à docência, configuram-se como elementos fundamentais do nosso processo de pesquisa e como desdobramento para o entendimento do mosaico que se configura com novas compreensões sobre o objeto de investigação.

Em um primeiro momento, foram feitas leituras reiteradas da carta, com o objetivo de nos impregnarmos dos relatos da professora, buscando unidades de sentido em suas mensagens a um professor de seu percurso de formação. Foi possível encontrar elementos importantes da escrita narrativa dela como meio de recontar e agradecer ao seu professor sobre como aprendeu com ele. Destacamos, dessa forma, palavras importantes como contribuições, reconhecimento, bronca, compromisso, respeito, admiração, gratidão, que nos chamaram a atenção para um maior aprofundamento sobre a história de vida vivenciada pela professora durante seu processo de escolarização. Notadamente, essas foram nossas primeiras unidades de sentido que tecem as memórias e as histórias sobre a experiência narrada pela professora e nos desperta o propósito de irmos à busca de evidências sobre esse percurso formativo.

A fim de constituir com maior afinco esta pesquisa narrativa, optamos por utilizar a entrevista para, assim, por meio do diálogo com a professora, conseguir compreender esse 
momento do ir e vir ao passado, na sua história, e poder argumentar sobre seus sentimentos para com a docência. A entrevista possibilitou que nos debruçássemos sobre a experiência vivida, na qual a professora pode (re)contar e (re)viver as memórias dela, permitindo-nos entender e encontrar filetes que configuram o mosaico do tornar-se professora de Ciências, elementos amplamente categorizados em forma de duas dimensões consideradas por nós eixos de análise da investigação.

\section{Discutindo os filetes do mosaico do vir a ser uma professora de Ciências}

A compreensão e a organização das unidades de sentidos e significados encontradas nos textos de campo, que expressam experiências de vida e formação relatadas pela professora, tanto na carta como na entrevista, resultaram em um texto de pesquisa constituídos por dois filetes de sentidos (categorias) que compõem o mosaico da presente pesquisa, os quais discutimos, em diálogo com a literatura pertinente, a seguir.

i. Afeto, emoções e sentimentos expressos na relação professor-aluna como reconhecimento de uma experiência vivenciada

Nem só de conteúdos as salas de aulas estão cheias, mas emoções e sentimentos que situam a inter-relação entre os participantes desse espaço em que se busca evitar a vivência monótona e mecânica e construir um ambiente mais colaborativo, sinergicamente. Frente a elementos expressos na carta e na entrevista, destacamos uma grande influência do apaixonar-se pelo professor, não em um sentido de amor, mas de empatia, respeito e admiração pelas características profissionais e humanísticas que eram vistas na relação do Prof. Geraldo (nome fictício) com a aluna, hoje professora. Das marcas temporais que lhe ficaram na memória referente ao professor, a colaboradora destaca a importante figura desse professor, descrevendo-o com afeto, ao dizer

Eu gostava muito dele. Como eu falei na carta, ele tinha essa coisa enérgica de entrar em sala de aula e jogar todo mundo pra cima, aquele professor bem bacana, bem descolado, o jeito dele andar, de falar, mas ele passava o conteúdo de uma forma legal também, de um modo alegre. Então, isso é uma coisa bem inspiradora para mim, porque eu tenho esse jeito mais truncada, mais fechada e eu sempre fico me criticando: 'Ah, eu também tenho que ser um pouco mais extrovertida, embora eu tenha que aceitar que esse é o meu jeito e eu não posso mudar abruptamente'. [Entrevista].

O afeto está presente nas narrativas, porém sob um olhar de aproximação e distanciamento sem que haja prejuízo ou distorções nas memórias e nas histórias de vidas que são relatadas, possibilitando um encontro entre os participantes da experiência, de forma consistente, capaz de expandir os filetes do mosaico em construção, dando espaço para o tempo em uma dimensão introspectiva e extrospectiva. O ambiente da introspecção está permeado por condições internas dos sujeitos como emoções, sensações, pensamentos, sentimentos e disposições pessoais, pelas quais é possível situar a experiência no tempo, no espaço e em escolhas individual e socialmente construídas.

Nessa ótica, a carta elaborada pela professora Renata tem elementos e evidências dessa introspeção, quando escreve: 
Pois então, um ano atrás, quando nos vimos, achei que não me reconheceria, mas, para a minha surpresa, lembrou meu nome, acho que com isso te marquei, certo? Espero que positivamente. A situação, devo confessar, foi estranha. Estranha, porque eu já não era mais sua aluna, mas uma professora que passava avaliando os trabalhos de uma certa especialização [...]. Foi mais estranho ainda porque tu eras um desses alunos e eu não me imaginava nessa situação. [Carta].

As percepções próprias, entrelaçadas com os aspectos sociais, caracterizam fortemente as experiências da experiência vivida, em um entrecruzamento espaçotemporal, desencadeado pelo espaço tridimensional da história (re)contada e (re)vivida pela professora Renata. Esse movimento narrativo aponta para limites topográficos de onde a experiência se situa, em âmbito subjetivo, implicando diretamente o olhar das narrativas para dentro de quem as conta, frente a um contexto constitutivo e relacional do fenômeno observado (CLANDININ; CONNELLY, 2015; MELLO, 2010).

A interpretação dos sentidos e significados vão para além das sensações dos personagens, extrapolam, inclusive, o olhar de quem lê uma narrativa com tendência intro ou extrospectiva, atribuindo-lhe a marca da complexidade da investigação narrativa, na composição dos movimentos temporais e, sobretudo, nos textos que podem, metaforicamente, criar novas compreensões sobre a experiência. Renata, em suas narrativas, volta seu olhar para dentro de si mesma, captando as próprias emoções daquilo que foi vivido e, provavelmente, estavam latentes em sua memória e, ao reviver narrativamente, caminha para si, por entre silenciamentos, lembranças, eventualidades e filetes de memórias que vão conduzindo a um novo olhar, privilegiando alguns aspectos em função de outros (CATANI; VICENTINI, 2003; JOSSO, 2004).

Observamos que Renata volta seus olhares para a situação de seu reconhecimento pelo professor, em uma situação inusitada, ao nos contar que, ao se reverem, em um momento posterior da época vivenciada em sala de aula, por não esperar um momento tão singular, de ser reconhecida por seu ex-professor que Ihe marcara tanto sua memória, como aluna. Esse fato Ihe foi tão significativo, que Renata a ele se refere, tanto na carta como na entrevista, ao (re)contar que

[...] não esperava! Eu não esperava, até mesmo porque na época que ele deu aula pra mim eu era adolescente e bem magra, tinha o cabelão, era bem diferente fisicamente mesmo e quando eu o vi eu estava até mais forte do que agora. Ele me olhou e quando eu falei 'Oi, Prof. Geraldo.!', acho que a minha voz também o fez lembrar. E quando ele falou meu nome, foi o ápice da felicidade. [Entrevista].

As sensações vividas no nosso movimento introspectivo dão sentido ao que foi vivido e agora revivido em uma situação de emoções, gerando mais significado à experiência dos acontecimentos, o que não parece ter fim e, em outro momento, isso pode se repetir, mesmo naturalmente. Uma aproximação é fortemente notada ou é desejada nas entrelinhas dos relatos, para que a interação do que foi vivenciado no passado crie uma maior tessitura no presente, como um mosaico da docência. Essa percepção é evidenciada pela professora, ao nos contar que o Prof. Geraldo 
[...] é uma figura que eu admiro bastante, como professor, que foi de fato referência para mim. Então, se a gente pudesse fazer uma disciplina junto no doutorado, tenho certeza de que teria muito que ele pudesse contribuir comigo. Ainda me vejo numa posição, mesmo de hierarquia, de que ele contribuiria muito mais, obviamente pelo tempo de experiência, do que eu poderia contribuir com a formação dele, por exemplo, assim colaborativa e coletivamente. [Entrevista].

Com o olhar de afetividade expresso anteriormente, a professora ainda acrescenta que:

Eu exaltaria mais o professor em sala de aula, a postura. Creio que prevaleceu bastante o que ele fez nos bastidores da escola, comigo e com os demais colegas; acabo falando muito de mim, óbvio. Mas eu lembro muito de ele falando com minha melhor amiga e outros colegas, que tinham problemas bem piores que os meus, em casa. Se eu pudesse escreveria também outras cartas aos professores que ficaram mais latentes, que ficaram mais lá pro finalzinho [da carta] e que compuseram esse mosaico. [Entrevista].

É possível perceber que a experiência de ambos se constitui de afetos, emoções e sentimentos para que, em um futuro não muito distante, houvesse a possibilidade de se encontrarem novamente e serem colegas mais próximos, em situações de colaboração mútua. Renata imagina que "se a gente pudesse fazer uma disciplina junto no doutorado, tenho certeza de que teria muito que ele pudesse contribuir comigo". Esse novo movimento de extrospecção, apesar de conectado ao primeiro, direciona a olhares para fora, que configuram condições daquilo que existiram ou podem vir a existir em um momento prospectivo, com outras pessoas ou com o meio, dando sentidos à própria experiência (re)vivida (CLANDININ; CONNELLY, 2015).

Tais caminhos dão sentido a uma dimensão relacional com o tempo e o espaço em uma dinâmica de ir e vir, sob a ótica da narrativa da professora, ganhando não só o espaço para a compreensão do fenômeno, mas para fazê-lo transitar por várias direções e sentidos, pois, pensar narrativamente, faz referência ao pensar relacional, que busca sentido de relações entre diferentes aspectos da experiência ou entre diferentes experiências. Esse inter-relacionamento da história (re)contada e (re)vivida pela professora Renata concretiza a narrativa dela em um modelo descritivo de situações pessoais e sociais, em conformidade, como subjetivamente pretende, narrar suas memórias (CARTER, 1993; CLANDININ; CONNELLY, 2015).

ii. O lançar-se ao passado em busca de evidências e contribuições do ser professora no tempo presente

Para entender como se constituem as memórias e histórias de vida, faz-se necessário lançar-se ao passado para captar evidências, marcas e expressões que se tecem no filete do mosaico do vir a ser professora. Essa retrospecção no deslocamento ao passado é um dos caminhos que situam o lugar no qual a professora Renata se centra e se localiza na história, a qual (re)afirma a sua própria história e a (re)vive, nas direções de análise de suas memórias. Ao narrar o passado vivido, em especial seu processo de escolarização, a professora narra se projetando ao futuro, frente a uma reconfiguração de si mesma, ao longo do tempo. 
Renata, tal como enfatiza na entrevista, escreve ao professor Geraldo, destacando sua personalidade. Dentre esses elementos, destacamos o início da carta: "Oi, Prof. Geraldo, tudo bem? Faz um bom tempo que nos falamos não é mesmo? Na última vez, quase não pudemos conversar. Agora, finalmente, criei coragem para escrever algo".

Ao notar esse elemento expresso na carta, buscamos saber que personalidade, figura ou profissional, o Prof. Geraldo viria a representar à professora pesquisada. Foi um momento de viajarmos no espaço tridimensional da pesquisa para o sentido do favorecimento da constituição da memória da professora, permitindo-lhe uma reconfiguração daquela pessoa tão explorada no retrospecto de sua introspecção. Esses lapsos são essenciais para nos entranharmos no passado, resgatando-o, frente a um posicionamento de transição temporal na pesquisa, a fim de compreendermos o que a professora é hoje, resultante dos eventos passados de sua escolarização. Nesse sentido, diz Renata:

O Prof. Geraldo foi, de fato, um professor muito marcante, embora a carta não seja apenas ele lá. A primeira parte dos três primeiros parágrafos são voltados para ele, lá pro último tem um mosaico de outros professores que aparecem também. Também fizeram parte desse período do ensino fundamental e médio que eu estudei nessa escola. Inclusive, era uma escola particular aqui em Belém, eu era bolsista nessa época, meu pai não tinha condições de trabalho e o Prof. Geraldo sempre foi um dos professores que viu um potencial em mim, latente, ou qualquer outra coisa, mas ele viu que eu me dedicava e ele sempre me incentivava bastante. [Entrevista].

As marcas memorialísticas expressas por Renata, descrevendo a figura do professor, caracterizam-se como um movimento de ir e vir, do passado ao futuro, passando pelo tempo presente da professora, como um meio de imersão nas características e detalhes de como o Prof. Geraldo se apresentava, seja na sua dinâmica pessoal ou profissional, em sala de aula. Não por acaso, trata-se de uma transfiguração da história de vida da professora, na qual suscitam marcas, sentimentos de gratidão, sensações e uma reflexão subjetiva de como o momento se desdobrava, para compreender, (re)viver e (re)contar suas histórias, sendo, sobretudo, uma forma de se reafirmar e discorrer em novas histórias de vida (CLANDININ; CONNELLY, 2015).

A dimensão do lugar em que ocorre o evento, a própria sala de aula, assim como o tempo em que flui o acontecimento, não podem ser considerados por nós elementos fixos, mas dinâmicos em suas essências, por estarem carregados de cores, sensações e sentimentos que se movimentam no tempo e no espaço para, assim, dar sentido e significado ao fenômeno investigado. As situações ocorridas não acontecem por acaso, pois permitem à professora dar um sentido de como entra na sua própria vida em um tempo passado e vai em direção ao tempo presente para poder se situar e dar significado àquilo que ia acontecendo de forma concatenada e, possivelmente, se projetar ao futuro, quando ainda expressa desejo de interação para novas aprendizagens com o professor Geraldo, talvez em uma disciplina de doutorado.

Outro fragmento nos mostra que o mosaico que representa seu percurso formativo inclui outros personagens, não somente a figura do Prof. Geraldo, apesar de este ser a mais emblemática na memória da professora. Outros professores perpassam sua memória, recontada dentro do seu inventário de escolarização e que, agora, são expostos de forma saudosista e com um significado importante para que pudesse chegar e compreender o seu presente. Nesse sentido, 
Tivemos esse contato, depois de mais ou menos 14 a 15 anos e eu achei interessante reportar, de contar na carta. Os outros professores que emergem também (sou péssima de nomes), embora eu me lembre do Prof. Geraldo, tinha uma professora de história que me deu os livros pra estudar. Como eu disse, eu era bolsista, e era só isso mesmo, não conseguia comprar material escolar e a professora percebeu que eu estudava bastante e ela falou: 'Eu vou te dar esses livros aqui. Você vai continuar estudando, né?'. Eu falei: 'Vou, professora!'. O episódio também que eu briguei com minha amiga foi outro professor, o de educação física, muito legal, que me incentivava bastante (tem que contar o episódio? A treta? rsrs). Eu dei uma bolada nela! Enfim, eu nem lembro por quê! Mas aconteceu! É aquilo do professor que conversa, que chega contigo, que não só diz 'oi' e vai pro quadro, apesar de serem professores que ficam para cima e para baixo, de uma escola para outra, mas tem aquele contato de sala de aula, de chegar ao seu lado, saber o que está acontecendo, perguntar porque está chorando, o que aconteceu em casa, quer falar? Quer beber alguma coisa? Saber se tomou café, senão ele paga. [Entrevista].

A professora Renata expressa que sua formação escolar foi um verdadeiro mosaico, termo expresso por ela em algum momento de sua colaboração na pesquisa. Bolsista em uma escola particular, dedicava-se aos estudos, o que era percebido por seus professores, como exemplificado pela doação de livros pela professora de História. Reconhece a dedicação dos professores, apesar do vai e vem de uma escola à outra, característico da vida de professores brasileiros. Vemos sentimento de gratidão nesse reconhecimento.

Do exposto, destacamos ainda que essas fases conturbadas estavam presentes na vida da professora, como a própria bronca que surge em sua fala, expressa na carta, ao mencionar "lembro-me de ter dito em nome da turma o quanto te admirava" e "aprendi com você a importância de ouvir os outros, dar uma segunda chance, a confiar". Esse movimento retrospectivo lança a professora ao tempo presente para dar sentido à sua ação como docente, pois, à medida que os filetes da memória vão se entrelaçando na história, ressignificam-se muitos dos seus saberes e das experiências hoje desenvolvidas no universo de sua práxis, como meio de transformação de si mesma e daqueles que estão próximos de si.

O relato nos direciona a uma metarreflexão, construída colaborativamente na experiência vivida e dando significação aos seus processos formativos, voltando os olhares da investigação à experiência da escolarização, enquanto a professora experienciava o papel de aluna, provocando-se em graus de complexidade da vida de adolescente, reinventando-se no passado e tecendo-se em uma miscelânea de experiências vividas no tempo passado e no vivido agora (ABRAHÃO, 2004). As experiências destacadas no movimento retrospectivo criam um momento de prospecção, em um ir e vir temporal, com os olhos do presente (GONÇALVES; NARDI, 2016), interpelado por filetes descritivos da memória e que inferem em uma interpretação que a professora descreve de sua vivência, em um processo de introspecção e extrospecção, do individual para o social, constituído pela docência.

Parte desses elementos espaço-temporais está inter-relacionada no corpo da carta e da entrevista realizada, por retratarem um vai-e-vem não combinativo, mas que se expressa nas interpretações das próprias interpretações descritas pela professora, em um sentido hermenêutico da experiência vivida. Para Larrosa (1996) e Clandinin e Connelly (2015), esse confronto do passado narrativo com nós próprios no presente nos deixam mais vulneráveis, dão-nos contato com a subjetividade e transformam nossas 
histórias tidas como secretas em histórias públicas, para serem analisadas e discutidas, mas nunca validadas ou buscar nuances de verdade, mas no sentido de criar um espaço de reconfiguração de compreensão da própria experiência e pelo prazer de narrar a si mesmo, em uma tessitura de espaço e tempo, que se combinam colaborativamente.

O tempo presente faz parte do entrelaçamento temporal, espacial e relacional que constituem as memórias e as histórias de vida em um movimento harmônico de situações e experiências que justificam o agora, o tempo presente em suas multifaces. Ou seja, o que constitui a professora hoje tem evidências nos eventos que ocorreram no passado, principalmente as encontradas nos fragmentos da carta e da entrevista, com nuances, marcas e expressões que sintetizam as narrativas. Nesse debruçar-se sobre os momentos retrospectivos, são apontados os caminhos que formaram e formam a professora em sua prática docente e marcam sua dinâmica pedagógica hoje, dentro das próprias complexidades da docência.

Nesse sentido, destacamos, nessa complexa volta ao passado, elementos que eram muito bem observados pela professora Renata como aluna, e, agora, são incorporados à sua vivência como docente. É importante frisar que as marcas do passado se projetam para o futuro e, em uma inversão do olhar, começamos a perceber coisas que não tínhamos percebido antes, mas que agora fazem mais sentido e dão significado ao presente. Ao comparar o Prof. Geraldo no passado e tempo presente da professora em sua docência, ela destaca que

Eu sou bem o oposto, a introvertida, mas eu tento muito conversar com meus alunos como ele fazia, sentava-se do lado, puxava a cadeira. Aconteceram casos lá onde eu estava trabalhando, de alunos que estavam com depressão, que tinham passado por situação de [tentativa de] suicídio e eu tive que mediar isso. Eram coisas que naquele momento eu poderia ter dito 'não comigo, fica com o psicólogo do campus, outra pessoa vai cuidar.' Mas eu tinha que me sentar com eles e conversar sobre, apesar que eu não ter o conhecimento técnico-profissional para falar, ou incentivar em sala de aula, pois eu lembro do Prof. Geraldo, que não gostava que fizessem bullying na sala de aula, apelidos de crianças, mas que ofendem. Uma coisa que estava acontecendo na minha última [turma] de calouros, tinha um aluno quilombola que a gente via, de fato, a carência nos estudos, aquele aluno que ficava de canto e todo mundo avacalhava com ele na sala. E eu de carão advertia os meninos, mas eles não paravam com isso; aqueles rebeldes sem causa. Eu ia conversar com ele e falei 'Está te incomodando isso? Tá te incomodando? Conversa com a gente! Fala, fala o que tá acontecendo em sala de aula'. E ele 'Não, professora, é assim mesmo!'. Até o jeito dele, não falava, parecia que a gente tinha que dar um empurrão na barriga dele pra sair algum som. Convidava ele pra estudar português, porque tinha dificuldade até pra ler os slides, no período que fosse. Depois que eu tive essa conversa, eu comecei a ver ele pedindo ajuda para colegas até de outras turmas e se dedicando um pouco mais, eu o vi evoluindo um pouco. Então, isso de conversar, de ir para o diálogo, mesmo que eu seja a pessoa mais introvertida que seja, eu tento que buscar ultrapassar esses obstáculos que eu tenho, de comunicação. [Entrevista].

O excerto anterior da entrevista de Renata e o que está a seguir nos permitem compreender que a professora se espelha no professor Geraldo, revivendo suas experiências como aluna dele e trazendo para a docência dela, no presente; seu exemplo de atenção, tanto ao conteúdo sob sua responsabilidade, quanto de escuta sensível (BARBIER, 1998) de seus alunos. Ela manifesta ter clareza que segue o professor Geraldo como modelo, ao dizer: 
Eu vejo a dedicação de quando ele chegava em sala de aula, como fazia tudo isso, era bem diferente dos demais professores que eu via mais que só se preocupavam em passar conteúdo. Eu tento fazer isso também, pra não chegar em sala de aula, se os alunos entenderam, ok! Senão, ninguém falava. Então eu vejo a dedicação que eu busco me espelhar. [...] Queria ser mais como ele! Na verdade, tentar me aproximar desse referencial que eu tenho a partir da figura dele. Falo também por ele ser enérgico, acho importante, estar mais próximo dos alunos, criar uma confiança na minha turma. [Não sei se falo isso na carta]. Mas alguns professores ficavam na frente, ou atrás, ou no meio, já ele transitava mesmo, chegava e se sentava com o pessoal da frente, no meio, ia lá com a 'Galera do Fundão'. Conversava, gostava de todo mundo, incentivava todo mundo. [Entrevista].

Para além do que a própria professora expõe, essas reflexões retrospectivas moldam as contribuições do que vem a sê-la no hoje, no presente, e a prospectam para o aprimoramento da sua própria ação didática em sala de aula, primando não só pela formação científica dos estudantes, mas contribuindo em sua formação humanística. Notadamente, há um desvelar dos aspectos da origem de como se constitui a professora, em seus aspectos epistemológicos e metodológicos, determinando fortes situações no campo pessoal e profissional, demarcando-se insights do seu processo de escolarização, mas que dão base à sua constituição docente.

Esse mergulho no passado se combina com outras peças do mosaico que configuram a professora de ciências, não somente pela sua formação hoje, mas pela singularidade expressa em suas narrativas, desenvolvendo um filete reflexivo pertinente no seu desenvolvimento da escolarização, junto a outras pessoas que vieram a contribuir positivamente e, no presente, possibilitam um olhar crítico e reflexivo sobre a demarcação da profissional que se consolida. Para Nóvoa (1995), os percursos seguidos pela pessoa em suas vivências acrescem ao desenvolvimento profissional que, no caso dos professores (e da professora em questão), desenha o entrançamento de sua própria ação.

\section{Palavras (In)conclusivas}

Após uma tessitura dos filetes que compõem esse mosaico do vir a ser uma professora de Ciências, destacamos que nosso objetivo maior esteve, desde o início da investigação, na forma de como se estabeleceu no processo de escolarização o encontro de Renata com a docência sendo, portanto, um olhar voltado às narrativas da professora e do contexto em que esteve inserida e não para a prioridade dada à Ciência em si mesma, pois a pesquisa parte da projeção desenvolvida em uma carta sobre as contribuições de um professor na vida dessa professora. Recai-se, dessa forma, em variantes que vão para além de uma experiência científica, para o olhar de formação escolar e humanística vivenciada ao longo da educação básica.

É nesse sentido que nos apropriamos da pesquisa narrativa como meio de compreendermos a rica e valorosa experiência pela qual a professora, em seu processo formativo da escolarização, perpassou e pudemos fazer um aprofundamento em suas memórias e histórias de vida, fazendo um movimento no espaço tridimensional das narrativas. O intuito da investigação não foi validar ou buscar verdades, mas compreender a experiência (re)vivida e (re)contada que teve grandes influências, sentimentos e contribuições para a práxis de uma professora em exercício hoje. 
As dificuldades começam no vai-e-vem do lançar-se ao passado da professora, pois, como pesquisadores, devemos imergir no contexto narrado, de modo a enxergar elementos que configuraram seu processo de escolarização. Surge, nessa paisagem, uma figura emblemática, a do Prof. Geraldo, o qual é expresso como um dos personagens principais encontrados na carta e na entrevista desenvolvida. A figura do professor vai para além da relação de sala de aula e conduz a um processo de atenção/escuta sensível ao/do ser humano e pela postura didática que torna a professora pesquisada um sujeito de sua própria experiência frente ao processo individual e social da escolarização. Assim observamos, através da carta e da entrevista, que existe um sentimento profundo de gratidão pelas contribuições que lhes foram ensinadas, mesmo diante de fortes obstáculos de vida, que culminaram no ser professora hoje.

Essa imersão afasta as dificuldades de se fazer uma investigação narrativa e nos lança para dentro da própria experiência, dando-nos sentido e significação no que lemos e no que ouvimos. A interpretação dos dados coletados busca no enlace da literatura uma argumentação mais consolidada para que possamos expor de forma clara e precisa a dinâmica relacional das histórias que nos é relatada. Frisamos que não somente a professora (re)viveu a sua história de vida, mas nós, como pesquisadores, entramos nesse mundo, vendo as cores dos ambientes, sentindo os cheiros dos espaços e compreendendo o mosaico que configura a professora Renata como docente.

A afetividade, manifestada por meio emoções e sentimentos expressos pela professora, são narrativas que constituem a investigação e não excluem a fidedignidade dos relatos, pois o pensar narrativamente cria um emaranhado de sensações que circulam em um movimento de ir e vir do processo de investigação e são fortemente observadas nas notas de pesquisa aqui desenvolvidas. Observa-se, em linhas gerais, que a narrativa da professora tem forte introspecção e extrospecção do que vem a ser, e do que foi vivido, dando um sentido mais amplo ao que se constituiu como uma professora de ciências no presente, dada sua capacidade de interação no ambiente da realidade experienciada, cumprindo os parâmetros da qualidade humana de contar histórias, voltar às suas memórias e assentar a sua cientificidade na pesquisa.

Para além das emoções (re)vividas e (re)contadas, destacamos que os relatos nos direcionam a caminhos realísticos do que se tornou a professora hoje, não sendo ideias fictícias ou necessárias para se desdobrar biograficamente, mas em um sentido de embasar a indiferença da experiência e tecer concepções que moldam sua profissão docente. $O$ reconhecimento é uma das peças fundamentais presentes na narrativa da professora e se configura como um dos movimentos que se retrospectam no processo de escolarização e buscam se prospectar em reflexões didáticas, pedagógicas e epistemológicas do processo formativo vivenciado.

A análise das diferentes informações obtidas com a professora nos faz dimensionar os filetes que conduzem a pesquisa narrativa e moldam esse mosaico de constituição da sua docência, que estão fortemente entrelaçados no espaço tridimensional da pesquisa narrativa e configuram o ser docente no presente. Para além das perspectivas e motivações, os resultados argumentados nesta investigação nos direcionam ao atendimento do objetivo proposto na pesquisa e, portanto, agregam-nos uma reflexão do profissional que a professora se tornou, nos aspectos de sua vivência relacional e em projeções que, em um futuro próximo, espelha a amplitude desse mesmo mosaico, não sendo por si só 
uma metáfora da pesquisa, mas um dimensionamento de vários filetes que constituem a experiência humana, em seus parâmetros individual e socialmente constituídos ao longo da vida.

\section{Referências}

ABRAHÃO, M. H. M. B. (org.). A aventura (auto)biográfica: teoria \& empiria. Porto Alegre: Ed. PUCRS, 2004.

BARBIER, R. A escuta sensível na abordagem transversal. In: BARBOSA, J. G. (org.).

Multirreferencialidade nas ciências e na educação. São Carlos: Editora da UFSCar, 1998. p. 168-199.

BURNIER, S.; CRUZ, R. M. R.; DURÃES, M. N.; PAZ, M. L.; SILVA, A. N.; SILVA, I. M. M. Histórias de vida de professores: o caso da educação profissional. Revista Brasileira de Educação, Rio de Janeiro, v. 12, n. 35, p. 343-358, 2007. DOI: https://doi.org/dgnmhv.

CARTER, K. The place of story in the study of teaching and teacher education. Educational Researcher, Irvine, v. 22, n. 1, p. 5-12, 1993. DOI: https://doi.org/bn4p97.

CATANI, D. B.; VICENTINI, P. P. Minha vida daria um romance: lembranças e esquecimentos, trabalho e profissão nas autobiografias de professores. In: MIGNOT, A. C. V.; CUNHA, M. T. S. (org.). Práticas de memória docente. São Paulo: Cortez, 2003. p. 149-166.

CLOSS, L. Q.; ROCHA-DE-OLIVEIRA, S. História de vida e trajetórias profissionais: estudo com executivos brasileiros. Revista de Administração Contemporânea, Rio de Janeiro, v. 19, n. 4, p. 525543, 2015. DOI: https://doi.org/fcjd.

CLANDININ, D. J.; CONNELLY, F. M. Pesquisa narrativa: experiência e história em pesquisa qualitativa. 2. ed. Uberlândia: EDUFU, 2015.

DELORY-MOMBERGER, C. Abordagens metodológicas na pesquisa biográfica. Revista Brasileira de Educação, Rio de Janeiro, v. 17, n. 51, p. 523-740, 2012. DOI: https://doi.org/fcjf.

FERREIRA, M. M.; FERNANDES, T. M.; ALBERT, V. (org.) História oral: desafios para o século XXI. Rio de Janeiro: Fundação Osvaldo Cruz, 2000. Disponível em: http://books.scielo.org/id/2k2mb. Acesso em: 6 out. 2020.

FRAIHA-MARTINS, F. Significação do ensino de ciências e matemática em processos de letramento científico-digital. 2014. 190 f. Tese (Doutorado em Educação em Ciências e Matemática) - Instituto de Educação Matemática e Científica, Universidade Federal do Pará, Belém, 2014. Disponível em: http://repositorio.ufpa.br:8080/jspui/handle/2011/8505. Acesso em: 18 out. 2020.

GIORDANO, A. A arte de contar histórias e o conto de tradição oral em práticas educativas. Construção Psicopedagógica, São Paulo, v. 21, n. 22, p. 26-45, 2013. Disponível em: https://cutt.ly/ MgetGfO. Acesso: 1 set. 2019.

GONÇALVES, T. V. O. Ensino de ciências e matemática e formação de professores: marcas da diferença. 2010. 272 f. Tese (Doutorado em Educação) - Faculdade de Educação, Universidade Estadual de Campinas, Campinas, 2010.

GONÇALVES, T. V. O.; NARDI, R. Aspectos epistemológicos da pesquisa narrativa presentes em teses e dissertações sobre formação de professores na área de educação em ciências e matemáticas, no período de 2000 a 2012. In: CONGRESSO IBERO-AMERICANO EM INVESTIGAÇÃO QUALITATIVA, 5., 2016, Porto. Atas [...]. Porto: Universidade Lusófona do Porto, 2016. p. 1065-1074. Disponível em: https://cutt.ly/FgetZUX. Acesso: 1 set. 2019.

GOODSON, I. Dar voz ao professor: as histórias de vida dos professores e o seu desenvolvimento profissional. In: NÓVOA, A. (org.). Vidas de professores. 2. ed. Porto: Porto Editora, 1992. p. 63-78. 
JOSSO, M.-C. Experiências de vida e formação. São Paulo: Cortez, 2004.

JOSSO, M.-C. História de vida e projeto: a história de vida como projeto e as "histórias de vida" a serviço de projetos. Educação e Pesquisa, São Paulo, v. 25, n. 2, p. 11-23, 1999. DOI: https://doi.org/ cd3mwz.

JOVCHELOVICH, S.; BAUER, M. W. Entrevista narrativa. In: BAUER, M. W.; GASKELL, G. Pesquisa qualitativa com texto, imagem e som: um manual prático. Petrópolis: Vozes, 2002. p. 90-113.

LARROSA, Jorge. Literatura, experiência e formação. In: COSTA, M. V. (org.). Caminhos investigativos: novos olhares na pesquisa em educação. Porto Alegre: Mediação, 1996. p. 133-160.

MELLO, D. M. Pesquisa narrativa: fenômeno estudado e método de pesquisa. In: ROMERO, T. R. S. (org.). Autobiografias na (re)constituição de identidades de professores de línguas: o olhar críticoreflexivo. Campinas: Pontes, 2010. p. 171-187.

MINAYO, M. C. S. Pesquisa social: teoria, método e criatividade. 34. ed. Petrópolis: Vozes, 2012.

MORAES, R.; GALIAZZI, M. C. Análise textual discursiva. 2. ed. Ijuí: Editora Unijuí, 2011.

NÓVOA, A. Formação de professores e profissão docente. In: NÓVOA, A. (org.). Os professores e sua formação. 2. ed. Lisboa: Dom Quixote, 1995. p. 13-33.

PASSEGGI, M. C. Injunção institucional e sedução autobiográfica: as faces autopoéticas e avaliativa dos memoriais. In: BARBOSA, T. M. N.; PASSEGGI, M. C. (org.). Memorial acadêmico: gênero, injunção institucional, sedução autobiográfica. Natal: EDUFRN, 2011. p. 103-132.

SMITH, J. Reflections on using life history to investigate women teachers' aspirations and career decisions. Qualitative Research, Cardiff, v. 12, n. 4, p. 486-503, 2012. DOI: https://doi.org/f36j94.

SOUSA, M. G. S.; CABRAL, C. L. O. A narrativa como opção metodológica de pesquisa e formação de professores. Revista Horizontes, Itatiba, v. 33, n. 2, p. 149-158, 2015. DOI: https://doi.org/fcjj.

STRYKER, S.; BURKE, P. J. The past, present, and future of an identity theory. Social Psychology Quarterly, USA, v. 63, n. 4, p. 284-297, 2000. DOI: https://doi.org/b5mj4n. 